\title{
EFFECT OF WATER SOURCES ON THE HEALTH OF RURAL CHILDREN: EVIDENCE FROM HOUSEHOLD SURVEY IN KWARA STATE, NIGERIA
}

\author{
R.O. BABATUNDE ${ }^{1}$, M.F. SALAMI ${ }^{1 *}$, J.O. AROKE ${ }^{1}$ \\ *E-mail: markmercy12@gmail.com
}

Received: Jan. 15, 2020. Revised: Feb. 03, 2020. Accepted: Feb. 08, 2020. Published online: Mar. 06, 2020

\begin{abstract}
Majority of the disease outbreak in developing countries have been attributed to contaminated water with children being the worst hit. Therefore, this study analyzed the effect of water sources on the health status of children under the age of 5 years in Ifelodun Local Government Area of Kwara State, Nigeria. Primary data was obtained through the use of semistructured interviews; 150 households with at least one child under five years were interviewed however; only 146 questionnaires were completed and found valid for analysis. The data was subjected to descriptive statistics, such as pie chart, bar charts. The results show that majority $(58.2 \%)$ of the children were males. Also, most $(83.5 \%)$ of the children were infants, i.e. within the age range of 0-2 years. Most (96\%) of the households had access to improved water sources of which protected dug well is the most accessible. Many $(42 \%)$ of the households reported that they experience periods of water shortage, this explains why water washed diseases (disease associated with poor hygiene in the face of water scarcity) was
\end{abstract}

the most predominant diseases reported among the children with 70 reported cases. These were closely followed by the water related insect vector diseases with 64 reported cases and then water borne diseases with 48 reported cases. Water based diseases rarely occurred in the study area. This study, therefore, recommends that effort should be geared towards provision of safe water all year round for the farming households. Also, insecticide treated nets should be made available for the children in the farming households so as to prevent insect bites.

Keywords: water washed diseases; incidence rate; dysentery; malaria; improved water sources; water shortage.

\section{INTRODUCTION}

Water is considered the most important of all public services. It is one of the most essential necessities of life after oxygen. However, rural communities in many developing nations have to obtain their drinking water from untreated surface sources,

\footnotetext{
${ }^{1}$ Dept. of Agricultural Economics and Farm Management, Faculty of Agriculture, University of Ilorin, Nigeria
} 
often situated far away from their residence. For instance, in many Nigerian rural communities, water supply infrastructures are still at developmental stage or are completely absent (Rossiter et al., 2010). Worldwide, waterborne diseases cause death and suffering of millions of people, especially children in developing countries. Recent survey by Majuru et al. (2011) estimated that 65 million Nigerians had no access to safe water. The situation was worse in the rural areas where only $24 \%$ of the population were said to have access to safe water.

Children are more vulnerable to the health hazards associated with unimproved water supply and sanitation; their immune, respiratory, and digestive systems are still developing, and children play in areas where contaminants may accumulate (Fayehun, 2010). In general, waterrelated diseases are caused by inadequacy of portable water supply and sanitation. However, they are broadly classified into four as waterborne diseases, water-based diseases, water-related vector diseases and water-scarce diseases (WHO, 2013).

Several studies (Adewumi et al., 2010; Shaheed et al., 2014; Osita et al., 2014) have been conducted revolving around water and agriculture productivity, incidence of water related diseases etc. Nevertheless, there seems to be dearth empirical evidences as regards the effect of water sources on health of children of farming households. The objectives of the study include: to examine the various water sources accessible to the farming households in the study area; to analyze the level of accessibility of improved water sources in the study area and to examine the rate of incidence of water-related diseases among the children of farming households in the study area.

\section{MATERIAL AND METHODS}

\section{Study area}

This study was carried out in Ifelodun local government area. Ifelodun is a Local Government Area in Kwara State, Nigeria, and is the largest local government area in Kwara State. It has an area of $3,435 \mathrm{~km}^{2}$ and a population of 206,042 at the 2006 Nigerian population census. The area is located between latitude $7^{\circ} 45^{\prime} \mathrm{N}$ and $9^{\circ} 30^{\prime} \mathrm{E}$ and longitude $2^{\circ} 30^{\prime} \mathrm{N}$ and $6^{\circ} 35^{\prime} \mathrm{E}$. The annual rainfall ranges between 1000 and $1500 \mathrm{~mm}$. Average temperature is $30^{\circ} \mathrm{C}$ and humidity range from $36-60 \%$. The major source of livelihood and occupation of the people in the area is farming.

\section{Source of data}

This study relies on primary data, which was harnessed through semistructured interviews. Relevant literatures were reviewed to access secondary information. The water related diseases considered by this study were those that are self-reported by the caregiver of the child. The caregivers were asked to report any water related disease that affected the child within the last 12 months. The caregivers of the children in each household were the respondents for this study.

\section{Sampling technique}

A three-stage sampling technique was adopted. The first stage was the 


\section{EFFECT OF WATER SOURCES ON THE HEALTH OF RURAL CHILDREN}

purposive sampling of five communities in Ifelodun local government area. The second stage was the use of snowballing sampling technique to generate a sampling frame. The sampling frame consists of households with at least one child within the age range of $0-5$ years in each community. The third stage involves the random selection of 30 farming households within the sample frame from each community. A total of 146 households that has at least one child within the age group of $0-5$ years was surveyed.

\section{Method of data analysis}

Descriptive statistical tools, such as percentages, frequency counts, bar charts and pie charts were used to analyze the data obtained. The choice of our analytical technique was informed by the nature of our research topic. This is because this research is within the socioeconomic and exploratory context.

\section{RESULTS AND DISCUSSION}

Table 1 describes the socioeconomic characteristics of the children within the age of 0 and 5 years of age in the farming households of the study area. Majority (58\%) of the children are males; $53 \%$ of them were between the age of 1 and 2 years. Most (71\%) of the children had not started schooling.

Table 1 - Socioeconomic characteristics of the children in the households

\begin{tabular}{lcc}
\hline Variable & $\begin{array}{c}\text { Frequency } \\
(\mathbf{N = 1 4 6 )}\end{array}$ & Percentage \\
\hline Gender & & \\
\hline Male & 85 & 58.2 \\
\hline Female & 61 & 41.8 \\
\hline Age (years) & & \\
\hline$<1$ & 44 & 30.1 \\
\hline 1 & 32 & 21.9 \\
\hline 2 & 46 & 31.5 \\
\hline 3 & 20 & 13.7 \\
\hline 4 & 3 & 2.1 \\
\hline 5 & 1 & 0.7 \\
\hline Educational status & \\
\hline Nursery & 42 & 28.7 \\
school & No. formal & 71.2 \\
education & 104 & \\
\hline \multicolumn{2}{c}{ Source: Field survey }
\end{tabular}

Source: Field survey

The result on Fig. 1 shows that the most of households $(96 \%)$ in the study area had access to improved water supply.

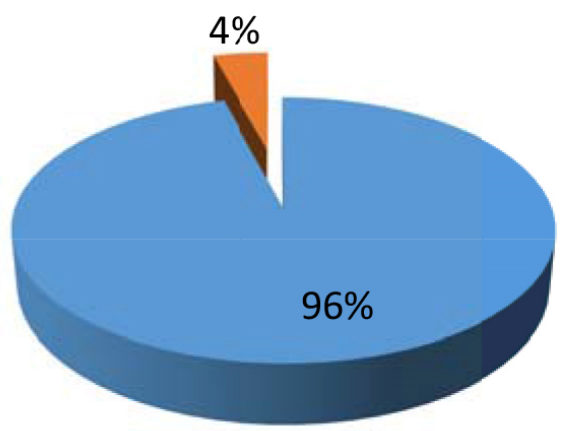

Improved

Unimproved

Figure 1 - Accessible water sources in the study area

Source: Field survey 
The result on Fig. 2 shows the breakdown of the various improved water sources that is accessible of the households in the study area; $48 \%$ of the households had access to protected dug well, $21 \%$ of the had access to public pipe borne water while, $31 \%$ of the had access to bore hole water.

The result on Fig. 3 shows that rain is the major source of unimproved water to the farming household in the study area. It reveals that $90 \%$ of the unimproved water the households make use of is rain water.

The result on Fig. 4 shows that $42 \%$ of the farming households in the study area experiences shortage of water. Shortage of water has an implication on the incidence of water washed diseases. This may probably explain why water washed diseases were reported to be the most prevalent in the study area.
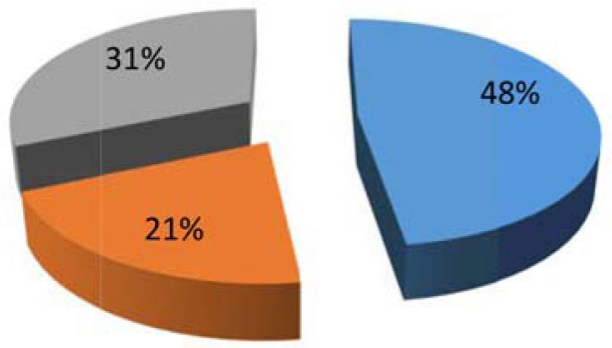

- Protected dug well

- Public/ Stand Pipe

- Tube well/ bore hole

Figure 2 - Types of improved water sources accessible to the households Source: Field survey

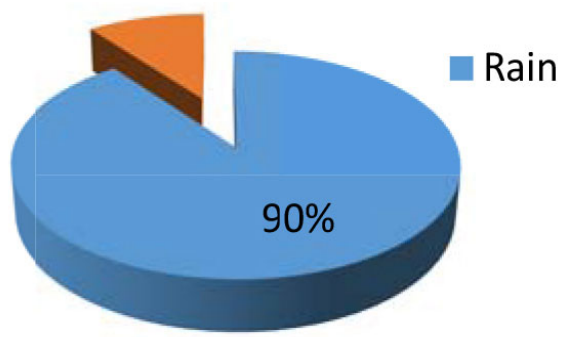

Figure 3 - Tyes of unimproved water sources accessible Source: Field survey

The result on Fig. 5 shows that only $36 \%$ of the farming households fetch water within their household premises; $25 \%$ of the farming households fetch their water within a distance of 501 meters to 1 kilometer

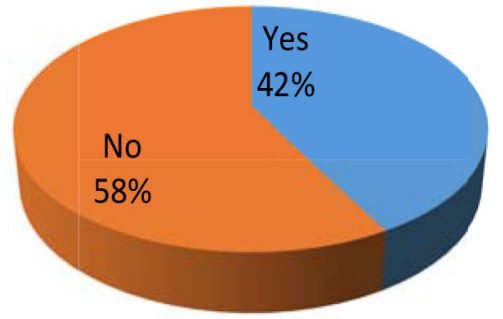

Figure 4 - Water shortage Source: Household survey, 2017

away from how. Moreover, 39\% of the household go as far a greater that 1 kilometer distance away for home to access water for their household use. 


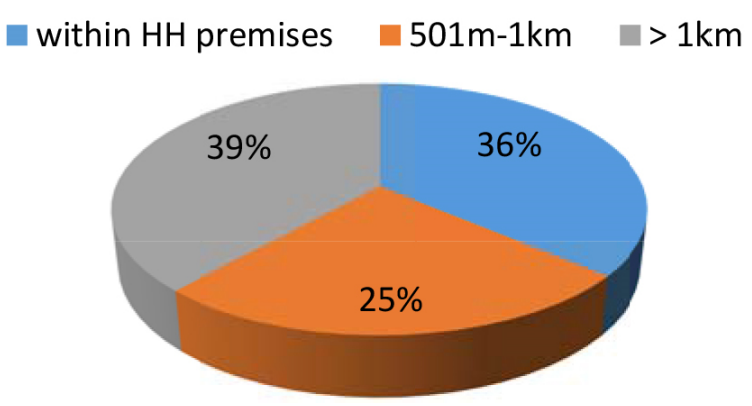

Figure 5 - Distance to water sources

Source: Field survey

Incidence of water related diseases among the children between ages 0 to 5 years in the study area

Fig. 6 reveals the rate of incidence of the four different groups of water related diseases. Water washed diseases were prevailing with an incidence rate of $47.9 \%$. The prevalence of water washed diseases may be probably due to the high level $(42 \%)$ of water shortages reported by the respondents. The water related insect vector diseases were reported as the next to water washed ones with an incidence rate of $43 \%$. Water borne diseases occurred in about $33 \%$ of the children, while the water based diseases were relatively scarce with only $2.1 \%$ rate of incidence. This may be probably because only a minority of the farming household gets water from surface water source, such as rivers, streams and lakes, were the water based diseases could be contracted.

water related insect vector
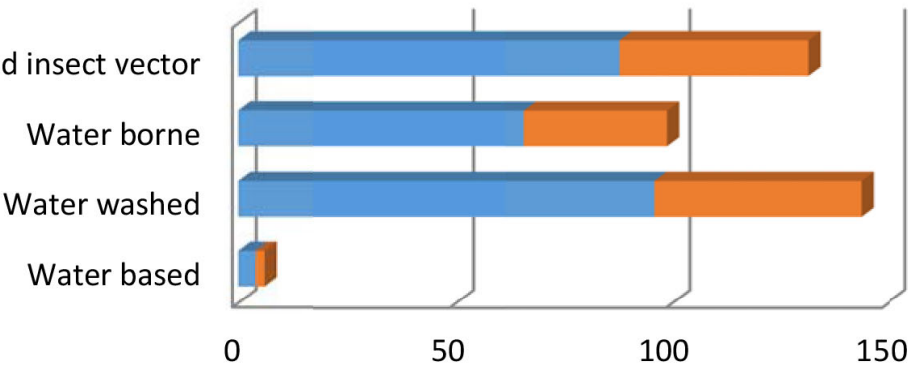

\begin{tabular}{|l|c|c|c|c|}
\cline { 2 - 5 } \multicolumn{1}{c|}{} & Water based & Water washed & Water borne & $\begin{array}{c}\text { Water related } \\
\text { insect vector }\end{array}$ \\
\hline arequency & 4 & 96 & 66 & 88 \\
\hline Percentage & 2.1 & 47.9 & 32.9 & 43.7 \\
\hline
\end{tabular}

Figure 6 - Water related disease groups

Source: Field survey 
The result on Fig. 7 shows that most $(81 \%)$ of the children infected with water washed diseases had dysentery. This corresponds with the to the findings of Lloyd et al. (1989), who in a study that examined the relationship between water-related disease and water quality in Lima, Peru, reported that dysenteries, which is a typical diarrhea disease, has an age distribution, which demonstrates the very high incidence of infection in the first year of life and children face a major risk of exposure to dysenteries during their first five years of life.
The result on Fig. 8 shows that malaria was the prevalent water related insect vector disease in the study area; $87 \%$ of the children reported to have water related insect vector disease had malaria.

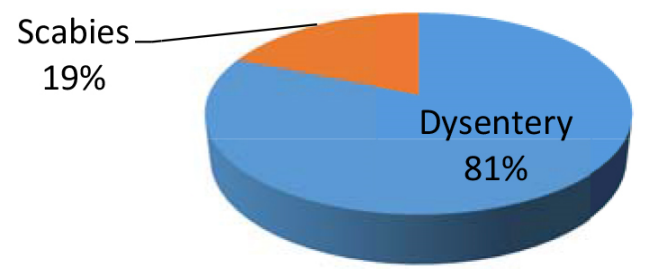

Figure 7 - Water washed diseases Source: Field survey

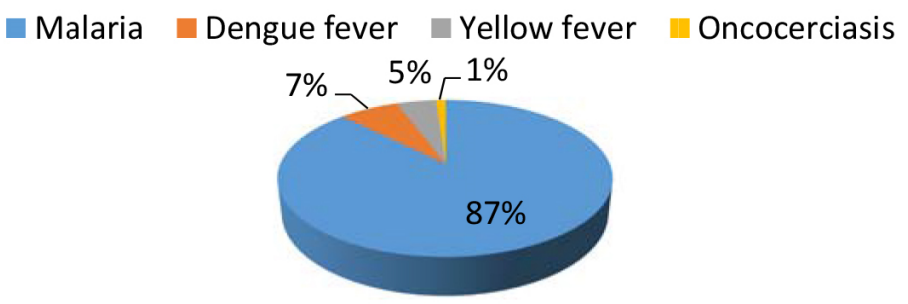

Figure 8 - Water related insect vector disease Source: Field survey

The result on Fig. 9 shows that the most prevalent $(71 \%)$ water borne disease among children under the age of 5 years is typhoid; $24 \%$ of the children with water borne disease were having giardiasis. Bacillary dysentery accounted for only $5 \%$ of the water borne diseases.

Thread worm was the only water based disease reported to infect children in the study area, as revealed in Fig. 10.

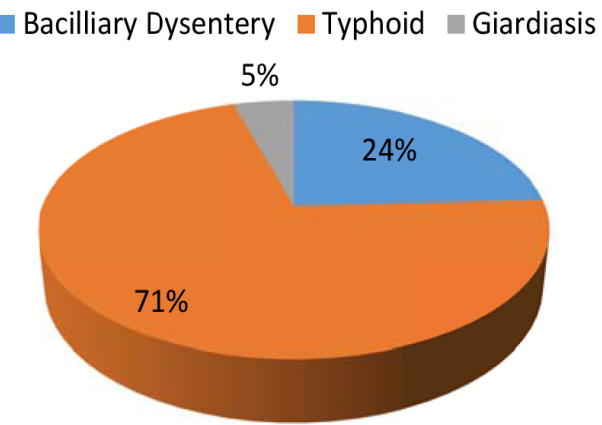

Figure 9 - Water borne diseases Source: Field survey 


\section{EFFECT OF WATER SOURCES ON THE HEALTH OF RURAL CHILDREN}

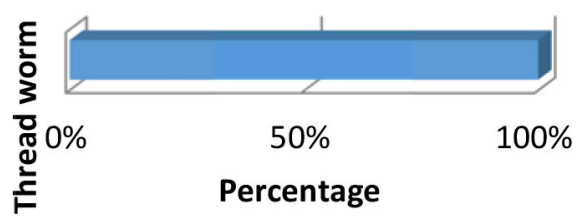

Figure 10 - Water based disease

Source: Field survey

\section{CONCLUSIONS}

Majority $(58.2 \%)$ of the children under the age of 5 years in the study area were males. Most (96\%) of the farming household that were survey for this study had access to improved water source. Protected dug well was the predominant improved water source in the study area. However, $42 \%$ of the households reported that they experience periods of water shortage. Water washed diseases (caused by lack of water) were the predominant disease group affecting the children under the age of 5 years in the study area. Malaria was the major water related insect vector disease that was reported.

The fact that these farming households had access to improved water source does not guarantee them having access to safe water. This is because the incidence of water borne diseases, such as typhoid, was relatively high, as compared to water based ones.

\section{RECOMMENDATIONS}

This study recommends that effort should be geared towards provision of safe water all year round for the farming households in the study area. Also, insecticide treated nets should be made available for the farming household. Special seminars should also be organized for the rural dwellers on the need to keep their environments clean and dry to prevent breeding of mosquitoes. They should also be educated on simple water treatment methods.

\section{REFERENCES}

Adewumi, M.O., Babatunde, R.O. \& Ayodele, O. (2010). The anthropometric status of farming households in Kogi State, Nigeria. Poster presentation at the Joint $3^{\text {rd }}$ African Association of Agricultural Economists and $48^{\text {th }}$ Agricultural Economists Association of South Africa Conference, Cape Town, South Africa.

Fayehun, O.A. (2010). Household environmental health hazards and child survival in sub-Saharan Africa. DHS Working papers, Demographic and Health Research, No. 74. Available online: http://dhsprogram. com/pubs/pdf/WP74/WP74.pdf (accessed on 15 May 2013).

Lloyd, B.J., Wheeler, D.C. \& Pardon, M. (1989). The relationship between water related diseases and water quality with particular reference to urban water supply in a developing country. Water SciTechnol., 21(3): 579-591, DOI: 10.2166/wst.1989.01 07

Majuru, B., Mokoena, M.M., Jagals, P. \& Hunter, P.R. (2011). Health impact of small- community water supply reliability. Int.J.Hyg.Envir.Health, 214(2): 162-166, DOI: 10.1016/ j.ijheh.2010.10.005

Ezeh, O.K., Agho, K.E., Dibley, M.J., Hall, J. \& Page, A.N. (2014). The impact of water and sanitation on childhood mortality in Nigeria: 


\section{R.O. BABATUNDE, M.F. SALAMI, J.O. AROKE}

evidence from demographic and health surveys, 2003-2013. Int.J. Environ.Res.Public Health, 11(9): 9256-9272, DOI:10.3390/ijerph1109 09256

Rossiter, H.M., Owusu, P.A., Awuah, E., Macdonald, A.M. \& Schäfer, A.I. (2010). Chemical drinking water quality in Ghana: water costs and scope for advanced treatment. Sci.Total Environ., 408(11): 23782386, DOI: 10.1016/j.scitotenv.2010. 01.053
Shaheed, A., Orgill, J., Ratana, C., Montgomery, M.A., Jeuland, M.A. \& Brown, J. (2014). Water quality risks of 'improved' water sources: evidence from Cambodia. Trop.Med. Int. Health, 19(2): 186-194, DOI: 10.1111/tmi.12229

WHO (2013). Report of the joint monitoring programme: progress on sanitation and drinking-water, UNICEF/WHO, New York, USA, 2013. 